\title{
YENI MEDYADA HALKLA ILIŞKILER ETiĞi MÜMKÜN MÜDÜR?
}

\author{
Ebru ÖZGEN*
}

\begin{abstract}
Özet
Yeni medya, bir PR kullanıcısının rüyası gibi görünebilir. Mesajı çeşitli yeni medya sitelerine yaymak kolaydır. Aslında bu bağlantıların birçoğu birbirine bağlantı verir, böylece birinde görünen bir mesaj bir anda pek çok sitede görünür. Halkla ilişkilerde temel konu hedef kitleye bilgiyi yaymak olsa da önemli olan bunu etik biçimde yapmaktır. Zor olan şey, etik olmayan eylemin yeni medyadaki etkisini ölçmektir. Yeni medya, halkla ilişkiler, halkla ilişkiler pratiği ve akademisyenler arasında giderek daha önemli roller oynamakta ve bu geleneksel etik paradigmaları yeni medyanın yarattığı sürekli değişen koşullara nasıl uygulayacağının zorluğuyla yüzleşmektedir. Halkla ilişkiler disiplininin, meslek olarak tanınması ve anlaşılması, kavramsal bir çerçeveye sokulması ve saygı görmesi için meslek ahlak kurallarına uygun hareket etmesi gerekmektedir. Geleneksel olan bile bu anlamda büyük bir sorunla karşı karşıya iken; "yeni medyada halkla ilişkiler ile ilgili etik nasıl oluşturulabilir?" Ne yazık ki, toplumumuzda etik sorunları önleyici yasal yaptırımlar konusunda büyük eksiklikler vardır. Ancak yeni medya, yeni ortamlarda ve yeni teknolojilerle hayatımızda giderek daha fazla yer kapladığı için "yeni medyada halkla ilişkiler etiği" konuşulmalı ve tartışılmalıdır.

Sonuç olarak yeni medya, insanların ilişkilerinin disiplini içinde giderek daha aktif ve önemli bir rol oynamaktadır. Öte yandan halkla ilişkiler ahlakı, geleneksel halkla ilişkilerin yeni paradigmaları ve yeni medya her geçen gün değişiyor ve her gün yeni engellerle karşı karşıya. Artık yeni medya ve halkla ilişkiler ayrılmaz bir süreçtir. Bu nedenle bu çalışmanın amacı, yeni medya çağında halkla ilişkiler etiği üzerine bir tartışma açmaktır.
\end{abstract}

Anahtar Kelimeler: halkla ilişkiler, etik, yeni medya, etik sorunlar, iletişim.

* Profesör Doktor, Marmara Üniversitesi, iletişim Fakültesi 


\title{
PUBLIC RELATIONS ETHICS IN THE NEW MEDIA/ IS IT POSSIBLE?
}

\author{
Ebru ÖZGEN*
}

\begin{abstract}
New media can look like a PR person's dream. It's simple to spread the message on the various new media sites. In fact, many of these link to each other so that a message appearing on one appears on the others. The main issue in public relations is to disseminate information to the target group, but what is important is to do it ethically. What's difficult is measuring the impact of unethical act in new media. New media plays an increasingly important role in public relations, public relations practices and academics. It faces the challenge of how to apply that traditional ethical paradigms to the constantly changing circumstances created by new media. There is a necessity for the discipline of public relations to act in accordance with professional codes of ethics in order to be recognized and understood as a profession, to be introduced into a conceptual framework and to be respected. Even in the traditional sense, we are facing a major problem which is "how can ethics related to the public relations be created in the new media?" Unfortunately, in our society, ethical problems cannot be brought to trial of preventive legal sanctions and there are major shortcomings in our society about legal sanctions to prevent ethical problems. However, the "ethics of public relations in the new media" should be spoken and discussed because new media is increasingly taking up more space in our lives with new environments and new technologies.
\end{abstract}

As a result; The new media has an increasingly active role in the discipline of people's relations and plays an important role. On the other hand, public relations ethics, new paradigms of traditional public relations, and new media are changing day by day and facing new obstacles. No longer new media and public relations are inseparable. Therefore, the aim of this study is to open a debate on the ethics of public relations in the age of new media.

Keywords: public relations, ethics, new media, ethics problems, communication.

* Professor Doctor, Marmara University, Faculty of Communication 


\section{Giriş}

Geleneksel anlamda henüz etik kodlarını halkla ilişkiler uygulamalarının içerisine tam olarak yerleştirememiş ve meslekleşme sürecinde var olan birtakım eksiklikler sebebiyle disiplinin algılanmasında birtakım sorunlar tam olarak çözülememişken, yeni medya kavramının hızla hayatımıza yerleşmesi ve dolayısıyla halkla ilişkiler disiplinin yeni medya eksenli gelişim göstermesi zorunluluğu ortadadır. Bu bağlamda yeni medya etiği tartışmasının halkla ilişkiler bağlamlı kapsamını ele almak, söz konusu yeni medya etiği olduğunda halkla ilişkiler etiğinin bu kapsamda nerede ve nasıl konumlanması gerektiğini tartışmak, konuyu çerçeveleyebilmek ve yeni medya düzeni içindeki halkla ilişkilerin etik kodlarını oluşturabilmek için bu çalışma bir ilk adım olabilir. Bu çalışmanın yapılabilmesi için görüşme, gözlem ve yazılı verilerin analizi ışı̆ında nitel araştırma teknikleri kullanılmış, toplanan verilerin analizi ile uygulamada karşılaşılan sorunlar sıralanmış ve çözüm üretme amacıyla bir eylem araştırması yapılmıştır. iletişim fakültelerinde görev yapmakta olan halkla ilişkiler araştırmacıları ve akademisyenleri bu çalışmanın temel araştırma evrenini oluşturmaktadır. Bu araştırma evreni içerisinden seçilen kişilerle gerçekleştirilen birebir ve derinlemesine görüşmeler, alan literatürü üzerinde yapılan taramalar, olgu üzerine yapılan doğrudan gözlemlerle elde edilen verilerin nitel teknikle analiz edilmesi sonucunda elde edilen bulgular, bu makalenin ana çatısını oluşturmaktadır.

\section{Halkla ilişkiler Etiğinde Temel Sorunlar}

Geleneksel halkla ilişkiler uygulamalarında gözlemlenen etik dışı sorunlar ve geleneksel medyanın kendi etik ilkeleriyle çelişen davranış biçimleri üzerine çalışmalar sürerken yeni medyada halkla ilişkiler etiği üzerine konuşmak çok da kolay değildir. Dinamikleri henüz yeni yeni kavranmaya çalışılan ve algılama yönetimi süreçlerini yöneten herkes için de varlık göstermeleri zorunluluk halini alan bir ortam olan yeni medya için etik ilkeleri oluşturmaya çalışmak oldukça zor görünmekle birlikte bir gerekliliktir.

Felsefenin en önemli disiplinlerinden biri olan etiğin kurucusu Aristo, yalnızca neyin iyi neyin kötü olduğu sorusuyla sınırlı kalmamış; bunun dışına çıkarak filozofların ahlak üzerine olan düşüncelerini de eleştirel bir açıdan ele alarak değerlendirmiş ve onları bir sistematiğe kavuşturmuştur. İnsan için doğru ve iyi yaşamın ne olduğu üzerine sistemli düşünceler milattan önce dördüncü yüzyılda filozoflarca düşünülmeye başlanmıştır. Etiğin kaynağı toplumdur. İnsanlar bir toplumu oluştururlar ve bir arada yaşayabilmek için de kurallar koyarlar. Dolayısıyla etiğin kaynağı insanların bir arada yaşama arzusu ve gereksinimidir.

Konuya eleştirel açıdan bakan İrfan Erdoğan'a (2006) göre ise; etik için gereksinim duymak ve onun üzerine konuşmak ancak ahlaksızlık, erdemsizlik ve kötülük olarak nitelenecek üretim ve ilişki tarzının olması ve bu durumdan rahatsızlık duyulması ile oluşur ve gelişir. Bu oluşum aynı zamanda ahlaksız- 
lığı üretenlerin de kendi ahlakını korumak için ahlaka sahip çıkmasını, ahlakı da kendi mülkiyetlerine, güç ve kontrol içine almasını ortaya çıkarır (Erdoğan, 2006: 4).

Son yıllarda gündemde hep temiz toplum hayali bulunmaktadır. İş dünyası, siyaset, bürokratlar, toplum, kirlenmiş toplumsal olaylardan söz etmekte ve bu durumdan dert yanmaktadırlar. Bu durumun en temel sebeplerinden birisi, temiz topluma olan talebin en şiddetli ve en samimi olduğu kesimlerde bile gerekli öz değerlendirmenin yapılmamasıdır. Bu anlamda, toplumsal temizliğin yapılabilmesi için iş çevrelerinin üzerine düşen, iş ve çalışma yaşamında "meslek etiği" konusunun daha çok tartışılır hale getirilmesidir (Uras, 2003).

Halkla ilişkiler disiplini açısından etik ilkelerinin ilk çerçevesini Ivy Lee, yayımladığı ‘ilkeler Deklarasyonu’nda çizmeye başlamıştır. Ivy Lee yayınladığı deklarasyonda kamuoyunun dürüstlükle bilgilendirilmesi gerektiği, gizliliğe yer olmadığı ve en iyi bilginin en doğru bilgi olduğunun altını çizmiştir. Ancak o günlerden bugünlere gelindiğinde halkla ilişkiler disiplini açısından etik ilkelerden söz etsek de uygulamada bu duyarlılığı görememekteyiz. Bu gözlemden yola çıkarak, geleneksel manada tam anlamıyla göremediğimiz etik davranışların yeni medya ortamlarında nasıl var edilebileceği ya da edilip edilemeyeceği önemli bir tartışma konusudur.

Son yıllarda halkla ilişkiler, yalanı kullanan, spin-doctor olarak görülen bir kavramla eş değer olarak görülmeye başlanmıştır. Pek çok eleştirel yaklaşım, halkla ilişkiler uygulamalarındaki manipülasyon ve propaganda ile olan yakınlığı nedeniyle zaten halkla ilişkileri etik dışı olarak yorumlamaktadır. Pek çok gazeteci, kanun yapıcı ya da meslekten olmayan kişiler arasındaki yaygın inanışa göre ise "halkla ilişkiler etiği" zıtlığın birleşimidir, gerçek dışıdır ve olasılık dışıdır (Bowen, 2007).

Kurumsal sorumluluk felsefesini geliştirmek, konuların kriz haline gelmeden çözümlenmesi, halkla ilişkilerde etik konusunun gelişimi için önemli ve gereklidir. Kurumsal sorumluluk aynı zamanda "kurumsal vicdan" oluşumu için de büyük önem taşır. PRSA (Public Relations Society of America), 2000 yılında halkla ilişkilerin etik kodlarını oluşturacak değerleri belli başlıklar altında toplamıştır:

- Savunma Etiği; sektörün ve pazarın sesi olmak, gerçekleri ve tüm bakış açılarını yansıtmak, toplumsal eleştirileri iyi okumak ve müşterinin iletişim sürecini yönetirken, bu sorumluluklarla yönetmek temel değerlerin başında olmalıdır.

- Dürüstlük; halkla ilişkilerin en önemli ilkesidir ve Ivy Lee'den bugüne dek vurgulanan en temel etik değerdir.

- Uzmanlık; bilgi, deneyim, araştırma ve eğitim temelli halkla ilişkiler uygulaması, disiplinin anlaşılır ve güvenilir olmasının zeminini oluşturacaktır.

- Özgürlük; baskı altında olmaksızın yapılan tüm eylemlerin sorumluluğu- 
nu üstlenmek etiğin temel yapı taşları arasındadır.

- Sadakat; hem temsil edilen danışanlara ve hem de hedef kitleye karşı sadakat önemlidir.

- Adalet; müşteriye, hedef kitleye, rakiplere ve tüm sosyal paydaşlara karşı adil olmak etiğin temelini oluşturmaktadır.

\section{Özne "Yeni Medya" Olduğunda Halkla ilişkiler}

Yeni medya ve yeni medyayı kullanan halkla ilişkiler üzerine gelişen literatür, bir yandan bu medyanın sunduğu olanakları çalışırken, diğer yandan da ortaya çıkardığı sorunlar üzerine odaklanma yoluna gitmektedir/gitmelidir.

Bugüne kadar gerek Uluslararası Halkla iliş̧kiler Derneği'nin (IPRA) Uluslararası Ahlak Yasası, gerekse de Halkla iliş̧kiler Danışmanları Derneği'nin Meslek ilkeleri vasıtalarıyla Halkla ilişskiler Meslek Etiği oluşturulmaya çalışılmıştır. Bu çalışmaların bir sonraki adımı olan etiğin uygulanmasına dair de pek çok araştırma yapılmış ve bu araştırmaların sonuçları ülkeden ülkeye farklılıklar göstermiştir. H. M. Lloyyd'un da belirttiği gibi, "halkla ilişkilerin halkla ilişkileri' konusunda yürütülebilecek en önemli faaliyet, bu etik ilkelere titizlikle uyulmasını sağlamaktır".

Bu görüşlerden yola çıkarak teknolojinin her geçen gün bize sunduğu farklı platformlar ve yeni medya araçları, halkla ilişkilerin de kaçınılmaz bir biçimde dijitalleşmesini zorunlu kılmış ancak geleneksel anlamda kendi etik ilkelerini uygulamada sorunlar yaşayan disiplin, dijital dünyanın içinde henüz etik çerçevesini de çizebilmiş değildir.

Bu temel problemden yola çıkarak öncelikli olarak yeni medyada halkla ilişkilerin etik sorunlarını belirlemek ve bu sorunların ışığında etik ilkelerin çerçevesini çizebilmek öncelikli adım olarak belirlenmelidir. Yeni medyada etik çerçeve çizildikten sonraki süreç ise uygulamada işlerliğinin nasıl kazandırılacağına ilişkin yöntemler tayin etmek üzerine olmalıdır.

Pavlik'e (2013) göre yeni medyada beş önemli boyut vardır; iletişim yöntemlerinin genişliği, hipermedya, yüksek okuyucu kitlesinin katılımı, dinamik içerik ve uyarlama (akt. Vardal: 2014). Iletişim yöntemlerinin genişliği konusu; yeni medya ortamlarında haberler, sadece yazılı ya da görüntülü değil metin, ses, video, grafik, animasyon ve 360 derece video gibi imkânların hepsi kullanılabilir. Hipermedya; hipermetin olarak da adlandırılan bağlantılardır. Kullanıcı bu bağlantı sayesinde haberle ilgili olan tüm bağlantıları görebilir, benzer haberlere anında ulaşabilir. Yüksek okuyucu kitlesinin katılımı, internet aktif bir iletişim aracı olduğundan, okuyucu kitle katılımı daha yüksektir ve ek olarak etkileşim olanağı sunar. Burada sözü edilen, teknik iletişim ve sosyal iletişim olanağıdır. Dinamik içerik ve uyarlama, haber içeriği online bir ortamda akıcı ve dinamiktir, güncelleme mümkündür ve bu durum yeni medya ortamlarını daha dinamik kılmaktadır ve ek olarak, sınırsız depolama (arşiv) ve kişiselleştirme 
(kendi medyasını oluşturma) söz konusudur.

Tüm bunlar kullanıcılar için olumlu özellikler olarak görülürken depolama ve kişiselleştirme özelliği aynı zamanda yeni medya ortamlarını kullanan tüm bireyler için dezavantaj oluşturabilecek konulardır ve yeni medya etiğinin sınırları çizilirken göz önünde bulundurulmalıdır. Kadir Has Üniversitesi tarafından 4 Haziran 2011 tarihinde düzenlenen "Yeni Medyada Etik: Etik 2.0" başlıklı çalıştayda ise şu sorun alanları ortaya konulmuştur (Binark ve Bayraktutan: 2013, 39):

- Özel yaşamın gizliliği

- Telif/patent hakları

- İçeriğin asıl kaynağının gösterilmemesi

- Üretilen içeriklerin olgunlaşmadan ve doğruluğun teyit edilmeden yayılması

- Kişisel verilerin güvenliğinin sağlanamaması

- Veri madenciliği

- Dijital gözetim

- Haber ve ticari enformasyonun sınırlarının belirsizleşmesi

- Yeni medya ortamındaki yoğun reklam içeriği

- Yanıltıcı etiketleme ve başlıklar

- Nefret söylemi

- Bireyin yeni medyada sadece tüketici olarak konumlandırılması

Yukarıda sıralanmış olan etik problemlere ek olarak Mutlu Binark ve Günseli Bayraktutan (2013) tarafından yapılan "yeni medyada etik sorunlar"a ilişkin saha araştırmasından çıkan farklı sorunlar şu şekildedir:

- Anonimlik duygusu: Anonimlik farklı amaçlar için kullanılabilir ve doğal olarak farklı sonuçlar da doğurabilir. Uydurma isimlerin arkasına saklanmış gerçek kimliklerle, büyük bir özgürlük ve güvenle görüş alışverişi, bilgi transferi, örgütlenme ve çeşitli hareketlere destek mümkündür, bu da özellikle otoriter siyasi rejimlerle mücadele/başa çıkma stratejisi olarak değerlendirilmektedir (Ess, 2010: 32).

- Mecranın yeniliği: Yeni medya ortamlarını kullananlar da yenidir, bir diğer deyişle, "dijital yerlilerin" etik anlayışından farklıdır.

- Troll olgusunun görülmesi: İnternet trollüğü, insanları tahrik ederek ve kızgınlıkla yazılmış cevaplar vereceklerini umarak, e-posta veya çevrimiçi grup mesajları göndermek olarak tarif edilmektedir. 
- Yayın içi sorunlar: insan kaynağı eksiği; özellikle gazetelerin çevrimiçi baskılarında yer alan okur yorumlarına ilişkin olarak bu sorun yoğun olarak dile getirilmektedir. Temelde okur yorumlarına ilişkin editörlük sürecini işletecek insan kaynağına yönelik hem nicel hem de nitel sorunlar olduğu vurgusu yapılmaktadır.

Bu sorunlara ek olarak düşünülmesi gereken başka bir konu da blogger'ların kurum ya da markaların ticari kaygılar nedeniyle kullanılması konusudur. Bu durum kapitalist anlayış içinde, insanların yanlış yönlendirilmesi için rahatlıkla kullanılacaktır.

Bir diğer konu, markalar hakkında olumlu içerik girilmesi için oluşturulan marka toplulukları da bir etik problem olarak değerlendirme içinde olmalıdır. Kimi zaman kendi öznel topluluklarını oluşturan bu gruplar adeta markaların hediye avına çıkmakta ve zaman zaman markalar için de sorun teşkil etmektedirler. Diğer yandan rakip markaları karalamak için gezinen gruplar da dürüstlükten ve doğruluktan uzak tavırlarıyla meslek etiğini zedelemektedirler. Halkla ilişkiler disiplini açısından da bu sorunlar etik kaygılar olarak değerlendirilmeli ve ek olarak;

- Kanıtlanmamış bilgiyi yayma,

- Kullaniciların olumsuz yorumlarını silme,

- Sahte hesaplar üzerinden kuruma sempati sunan olumlu mesaj içerikleri girme gibi davranışlar, problemin diğer tarafını oluşturmaktadır.

Yeni medya kullanımı, yaşanan güncel olaylar karşısındaki ani toplumsal reflekslerde çoğu zaman savunulan düşüncenin propaganda aracı olarak değerlendirilebilir. Bu kişileri "yeni medya muhabiri" veya "yazarı" olarak tanımlayabiliriz. Belki de burada Barack Obama'nın seçim kampanyası sırasında aktif olarak kullandığı ve "Yes, We can" mottosunu tüm dünyada aktif olarak yerleştirmesinde yeni medyanın gücünü hatırlayabiliriz. Öyle bir güç ki, bu ifade ABD Başkanlık Seçimlerini etkiledi. Bugün ise bu güç bir lobi faaliyeti haline geldi. Troll hesaplar belli bir algıyı yönetmek adına aralıksız çalışmakta ve kitleleri peşinden sürüklemektedir. Bazen bir fotoğraf bazen de bir video kitleleri manipüle etmeye yetebilmektedir.

Yeni medya, doğası gereği kullanıcısına veya hedef kitlesine etkileşim olanağı sağlamaktadır. Elektronik e-postalar ya da bilgisayar oyunları da yeni medya aracı olarak kabul edilmektedir. Bu nedenle hepsinin kendi içinde etik ihlalleri farklılık göstermekte ve ayrı çalışma konuları olarak incelenmelidir. Ancak toplumu sosyal açıdan en çok etkileyen ise yeni medyayı güç olarak kullanabilenlerin, bu gücü milyonlara yönelik "kara propaganda" aracı olarak harekete geçirmeleridir. En basit örnek Facebook üzerinden şovenizm yapmak, belirli çıkarlar için insanları yanlış yönlendirmek halkla ilişkiler adına en önemli etik problem olarak karşımıza çıkmaktadır. 
Önemli bir diğer etik problem ise, son zamanlarda yeni bir meslek alanı olarak karşımıza çıkan "sosyal medya uzmanlığı" olgusudur. Gerçek anlamda uzmanlığı olmayan, sosyal medyanın kendi dinamiklerinin farkında bulunmayan, sadece sosyal medya hesapları olması nedeniyle bile kendini uzman ilan eden pek çok kişinin çeşitli markaların hesaplarını bilinçsizce ya da stratejisi olmadan yönetmeleri de, etik problem olarak karşımıza çıkmaktadır.

\section{Sonuç ve Öneriler}

Bu makalede ortaya konulan gözlemler ve değerlendirmeler de göstermektedir ki tüm iletişim/halkla ilişkiler çevrelerinin asıl çabası "Yeni medya üzerinde halkla ilişkiler disiplini etik çerçevesini nasıl çizmeli?" sorusunu sormak ve bu soruya olabildiğince kapsamlı yanıtlar bulmak olmalıdır. Mesleğin yeni medyadaki uygulama alanlarının başında, kullanıcıları izleme (monitoring), hedef kitle takibi olduğu bilinmektedir. Meslek, kurum içi bakıştan uzaklaşarak kurum ve hedef kitle arasında ortada bir yerde durabilmeli ve dijital platform hedef kitleyi izleme olduğu kadar, hedef kitleye kulak verme-dinleme-görüş ve önerilerini dikkate alma boyutuna da önem vermelidir. Dijital platform kâr amaçlı ticari uygulamalar dışında toplumsal projelerin yaşama geçirilmesinde de ağırlıkla kullanılabilirse eğer, bu algı olumlu açıdan yön değiştirebilir. Mesleğin sosyal boyutu, sosyal medyada daha fazla temsil edilebilir ve aslında meslek algısına yönelik bir takım problemlerin üstesinden gelmede yardımcı olabilir.

İnsanların yeni medya okur-yazarlı̆ı konusunda eğitilmesi/bilinçlendirilmesi gereği de önemli bir noktadır. Bu amaçla bilgilendirme toplantıları ve farkındalık çalışmaları yapılmalıdır.

Sosyal medya uzmanlığı ve halkla ilişkiler adı altında düzenlenen sertifika programları denetlenmelidir. Bu konuda iletişim meslek örgütlerine önemli görevler düşmekte ve uygulanabilirliği olan yasal yaptırımların üzerinde çalışılması önem taşımaktadır.

Yeni medya davranış modelleri önemli bir araştırma konusudur. Her yıl konuyla ilgili araştırmalar yapılmalı ve sonuçları üzerinden stratejiler geliştirilmelidir. Yeni medya etiği yine aynı yollar üzerinden, yani yeni medya üzerinden oluşturulmalı ve yayılmalıdır. Bu yolla bilgilendirme içerikleri oluşturulmalı, ücretsiz seminerler ve sertifika programları düzenlenmelidir. Gerek meslek etiği üzerinde çalışan akademisyenlerin, gerekse de meslek örgütlerinin bu konudaki hassas tavırları ve ısrarları önemli bir ilk adımı oluşturacaktır.

Uzun soluklu bir iletişim stratejisi ve eğitim içeriği "yeni medyada halkla ilişkiler etiği" için temel oluşturacaktır.

Filtreleme sistemleri ile sanal kimlikler ve sanal topluluklar engellenmelidir.

Geleneksel halkla ilişkiler etik kodları en iyi şekilde yerleştirilmeli ve bu sayede yeni medya etik kodları oluşturmaya yönelik çalışmalar başlayabilmelidir. 
Aksi takdirde sadece yazılarda kalan bir tartışmanın ötesine geçememiş ve hep yerimizde saymış oluruz.

\section{Kaynakça}

Ataberk, Ü. (2005). "iletişim Teknolojileri ve Yerel Medya iç̧in Olanaklar". Sevda Alankuş (ed.) Yeni iletişim Teknolojisi ve Medya. ìstanbul: PS iletişim Vakfı Yayınları.

Binark, M. (2013), Yeni Medya Çalışmaları. Ankara: Dipnot Yayınları.

Binark M. ve Bayraktutan (2013). Ayın Karanlık Yüzü: Yeni Medya ve Etik. İstanbul: Kalkedon Yayınları.

Bowen, S. (2007). Ethics and Public Relations. www.instituteforpr.org/ethics-andpublic-relations.

Erdoğan, i. (2006). "Medya ve Etik". http://irfanerdogan.com/makalelerson/medyaveetik.pdf.

Uras, G. (2003). “Çalışanlara Göre İşyerlerinin Sadece \%24.8'i iş̧ Etiğine Özen Gösteriyor". Milliyet. http://www.milliyet.com.tr/2003/11/11/business/ bus09.html. 05.09.2006.

PRSA. (2000). Code of Ethics. http://www.prsa.org/AboutPRSA/Ethics/documents/ Code\%20of\%20Ethics.pdf.

Vardal, B. "Yeni Medya ve Etik". aasrc.org/conference/wp-content/uploads/2015/ 02/Yeni-Medya-ve-Etik.docx. 
ETKILEşim 63 